\title{
Genetic Analysis of Flower Size and Production in Diploid Rose
}

\author{
Shuyin Liang, Xuan Wu, and David Byrne ${ }^{1}$ \\ Department of Horticultural Sciences, Texas A\&M University, College Station, TX 77843-2133
}

AdDitional INDEX wORDs. Rosa, abiotic stress, heat tolerance, high temperature, flower yield, heritability, breeding

\begin{abstract}
This project examined rose $($ Rosa $\times$ hybrida) performance by measuring flower size and flower numbers per inflorescence in spring, summer, and fall seasons (mean temperatures $21.7,30.0$, and $18.1{ }^{\circ} \mathrm{C}$, respectively) in interrelated rose populations. Populations and progeny differed in flower size as expected. Heat stress in the summer season decreased flower diameter (18\%), petal number $(17 \%$ to $20 \%)$, and flower dry weight $(32 \%)$. Analysis of variance (ANOVA) showed a significant population/progeny $\times$ heat stress interaction for flower diameter indicating that rose genotypes responded differentially to heat stress. Flower size traits had moderate low to moderate narrowsense $(0.38,0.26-0.33$, and 0.53 for flower diameter, petal number, and flower dry weight, respectively) and moderately high to high broad-sense $(0.70,0.85-0.91$, and 0.88 for flower diameter, petal number, and flower dry weight, respectively) heritability. Genotype $\times$ environment $(G \times E)$ variance (population/progeny $\times$ heat stress) for flower diameter accounted for $\approx 35 \%$ of the total variance in the field experiment indicating that heat stress had moderate differential genotypic effects. However, the genetic variance was several fold greater than the $G \times E$ variance indicating selection for flower size would be effective in any season but for the selection of a stable flower size (heat tolerant) rose genotype, selection would be required in both the cool and warm seasons. Seasonal differences in flower productivity of new shoots did not appear related to heat stress but rather to the severity of pruning conducted in the different seasons. The number of flowers produced on the inflorescence had moderate narrow-sense $\left(h^{2}=0.43\right)$ and high broad-sense $\left(H^{2}=0.75\right)$ heritability with a moderate genotype $\times$ pruning effect that explained about $36 \%$ of the variance.
\end{abstract}

Roses (Rosa sp.) have been one of the most popular floral decorations for the past 5000 years and are commercially used as garden plants, cut flowers, and for food/medicinal/fragrance industrial use (Gudin, 2000; Shepherd, 1954; Zlesak, 2006). They were originally domesticated in the northern hemisphere and have been spread throughout the world (Krussmann, 1981). This widely used ornamental crop has a diversity of plant types, flower shapes, and flower colors.

Roses rank in the top five most popular cut flowers in the United States and in the top five ornamental crops in the world (Debener and Linde, 2009; Hodges et al., 2015). In 2003, the estimated production of rose was 18 billion cut stems, 60-80 million potted plants, and 220 million garden plants (Blom and Tsujita, 2003; Pemberton et al., 2003; Roberts et al., 2003). The value of the world rose production was estimated at 24 billion Euros in 2008 (Heinrichs, 2008) and the Dutch rose cut flower market was estimated to be worth $\$ 10$ billion (Ahmad et al., 2010). Recently, the annual value of the North American garden rose industry was estimated at $\$ 1$ billion (Vineland Research and Innovation Center, 2013). Unfortunately, because of the lack of well-adapted cultivars, the sale of garden roses has decreased $25 \%$ to $30 \%$ during the past 20 years (Byrne et al., 2010; Hutton, 2012; Pemberton and Karlik, 2015).

High temperature or heat stress is one of the major limiting abiotic factors for plant growth throughout the world. Heat stress in rose causes leaf damage, flower abscission, and

Received for publication 24 May 2017. Accepted for publication 29 June 2017. This work was partially funded by the Robert E. Basye Endowment in Rose Genetics and the USDA's National Institute of Food and Agriculture (NIFA) Specialty Crop Research Initiative projects, "RosBREED: Combining Disease Resistance with Horticultural Quality in New Rosaceous Cultivars" and "Combating Rose Rosette Disease: Short Term and Long Term Approaches." ${ }^{1}$ Corresponding author. E-mail: dbyrne@tamu.edu. decreased flower size and quality which greatly reduce market value. The average daily maximum temperatures $8-14 \mathrm{~d}$ before a flower opens affects flower dry weight significantly (Greyvenstein et al., 2014). Excessive heat stress may cause a negative effect on longevity and quality of a cut rose (Marissen, 2001; Moe, 1975; Wahid et al., 2007) as well as on flower size, petal number, flower color (intensity, anthocyanin concentration), flower number (by increasing flower abscission), flower productivity (percent flower canopy cover, leaf area), the number of vegetative nodes before flowering, the time to flowering, and leaf appearance in both cut flower (Dela et al., 2003; Gitonga et al., 2014; Shin et al., 2001) and garden roses (Greyvenstein, 2013; Greyvenstein et al., 2014). High temperature also reduced flowering stem length and plant height because the plant reaches the florogenesis and anthesis stage much earlier (Gitonga et al., 2014). With diploid roses, a heat shock treatment $\left(1 \mathrm{~h}\right.$ at $\left.44{ }^{\circ} \mathrm{C}\right)$ decreased flower diameter $(15.7 \%)$, petal number $(23.3 \%)$, and flower dry weight $(16.9 \%)$. A genetic analysis indicated that flower size is heritable although the heat stress uniformly affected all populations/genotypes when examining petal numbers and flower dry weight. However, for flower diameter, there was a small genotype $\times$ environment effect indicating that the populations/genotypes responded differentially to heat stress. Thus it appears flower size heat tolerance exists in diploid roses (Liang et al., 2017). A rose with high temperature tolerance and consistent flowering during the warm season will contribute to maintaining a good landscape appearance (Greyvenstein et al., 2014).

As variation in heat tolerance has been detected among rose cultivars and populations in their ability to maintain acceptable flower size and flower production under heat stress (Greyvenstein, 2013; Greyvenstein et al., 2014; Liang et al., 2017), 
this project documented the effect of summer heat and assessed the genetic basis of heat tolerance as expressed in the changes of flower diameter, petal number, flower dry weight, and flower number per inflorescence in a field setting for diploid roses. The long-term goal of this project is to develop high temperaturetolerant garden rose cultivars that are well adapted to the southern United States and similar hot humid climates.

\section{Materials and Methods}

Plant material. Since 2010, the Texas A\&M University Rose Breeding and Genetics program has been assessing the ability of rose germplasm to produce flowers in the cool (April/ May and November) as compared with the warm (August) season in Texas (Byrne et al., 2012). Using this approach, roses such as 97/7-2, 'Red Fairy', 'Sweet Chariot', 'Vineyard Song', and 'Little Chief' were identified as very sensitive to high temperatures as they produced abundant flowers in the cool season, but few during the warm season. By contrast, the rose breeding lines M4-4, J06-20-14-3, and J06-30-3-6 produced abundant flowers throughout the year and thus were classified as heat tolerant with respect to their flower productivity. The diploid rose populations were created by intercrossing heattolerant breeding lines and heat-sensitive roses (Table 1). The heat tolerance in the rose breeding lines was derived by introgressing heat tolerance from the wild rose species Rosa wichurana into ever blooming commercial rose germplasm ('Old Blush' and 'Ducher'). Ten populations were studied in 2013 and 2014, and nine populations were studied in 2015. The change was made to include those populations with larger numbers of seedlings available. In both cases, the germplasm studied was similar. The seedlings of the diploid populations were planted at a $1 \times 1 \times 3.5-\mathrm{m}$ spacing in a field $2.5 \mathrm{~km}$ from Texas A\&M University at College Station (lat. $30.65^{\circ} \mathrm{N}$, long. $96.32^{\circ} \mathrm{W}$ ). One plant per seedling was planted on raised beds in rows oriented east to west in an open field in 2013 or 2014. Black landscape cloth weed barrier was placed around each plant for weed control. Irrigation was applied as needed and fungicides or pesticides were not used during evaluation. Each plant was hard pruned (reduced plant size by $50 \%$ to $75 \%$ ) at the end of the winter in February/March and light pruned (reduced plant size by $25 \%$ to $40 \%$ ) in both June and September to restrict plant size and induce new growth.

Temperature. The temperature data were obtained from the $\mathrm{Na}$ tional Oceanic and Atmospheric Administration (NOAA, Silver Spring, MD) for the College Station Easterwood Field (station code
GHCND:USW00003904) which is about $2 \mathrm{~km}$ from the research field. The temperatures during the 4 weeks before flowering, which is the critical time period during which the flower size is influenced by the temperature (Greyvenstein et al., 2014), was about $10^{\circ} \mathrm{C}$ higher in the summer (August, mean temperature $30{ }^{\circ} \mathrm{C}$ ) as compared with the temperatures experienced in the spring (April) and fall (November), when temperatures averaged 21.7 and $18.1^{\circ} \mathrm{C}$, respectively [Table 2 (National Oceanic and Atmospheric Administration, 2015)].

DAta collection. In 2013 and 2014, flower size was quantified by counting the number of petals per flower. In 2015, the work was expanded to include other measures of flower size and flower production. Flower size (flower diameter, flower petal number, and flower dry weight) and flower production (number of flowers per primary/secondary/tertiary inflorescence) were measured during the spring (April), summer (August), and fall (November) with an average temperature of 21.7, 29.4-31.1, and 16.4-20.2 ${ }^{\circ} \mathrm{C}$, respectively (Table 2). Flower size data were collected from at least three fully open flowers [flower development stage 10 (Ma et al., 2015)] randomly chosen from the primary inflorescence in each plant. Flower diameter (centimeters) was measured in the field. Flowers (without pedicel) were put into paper envelopes $(9 \times$ $16.5 \mathrm{~cm}$ ) and were dried at $80{ }^{\circ} \mathrm{C}$ for at least $3 \mathrm{~d}$ before weighing. Petal count (done in the laboratory) represents the number of normal petals and petaloids (irregular shaped petals). In rose, flower petal number is controlled by a major dominant

Table 1. Diploid rose populations used for flower size and production characterization in the field at College Station, TX. Heat-sensitive rose genotype names are underlined.

\begin{tabular}{|c|c|c|c|c|}
\hline Population & Female parent & Pollen parent & Avg population size (no.) ${ }^{z}$ & Yr collected \\
\hline$\overline{\mathrm{OB}} \times \mathrm{J} 3-6$ & Old Blush & J06-30-3-6 & 52 & 2013,2015 \\
\hline $\mathrm{TF} \times \mathrm{J} 3-6$ & The Fairy & J06-30-3-6 & 4 & 2013 \\
\hline $\mathrm{OB} \times \mathrm{M} 4-4$ & $\overline{\text { Old Blush }}$ & M4-4 & 11 & 2013 \\
\hline $\mathrm{SC} \times \mathrm{M} 4-4$ & Sweet Chariot & M4-4 & 43 & 2013,2015 \\
\hline $\mathrm{J} 4-6 \times \mathrm{RF}$ & J06-28-4-6 & $\underline{\text { Red Fairy }}$ & 35 & 2013,2015 \\
\hline $\mathrm{J} 3-3 \times \mathrm{RF}$ & J06-30-3-3 & $\overline{\text { Red Fairy }}$ & 6 & 2013 \\
\hline $\mathrm{VS} \times \mathrm{J} 14-3$ & $\underline{\text { Vineyard Song }}$ & J06-20-14-3 & 5 & 2013 \\
\hline $\mathrm{J} 14-3 \times \mathrm{VS}$ & J06-20-14-3 & $\underline{\text { Vineyard Song }}$ & 64 & 2013,2015 \\
\hline $\mathrm{J} 14-3 \times \mathrm{SC}$ & J06-20-14-3 & Sweet Chariot & 26 & 2013,2015 \\
\hline $\mathrm{M} 4-4 \times \mathrm{SC}$ & M4-4 & $\overline{\text { Sweet Chariot }}$ & 11 & 2013 \\
\hline $\mathrm{J} 14-3 \times \mathrm{LC}$ & J06-20-14-3 & Little Chief & 30 & 2015 \\
\hline $\mathrm{J} 14-3 \times \mathrm{RF}$ & J06-20-14-3 & Red Fairy & 73 & 2015 \\
\hline $\mathrm{OB} \times \mathrm{RF}$ & $\underline{\text { Old Blush }}$ & Red Fairy & 11 & 2015 \\
\hline M4-4 × 97/7-2 & M4-4 & $\underline{97 / 7-2}$ & 18 & 2015 \\
\hline
\end{tabular}

${ }^{\mathrm{z}}$ Population sizes varied with the data taken.

Table 2. Temperature means and precipitation for the 4-week period before measuring flower size and production on diploid rose populations at College Station, TX, for spring (April), summer (August), and fall (November) (National Oceanic and Atmospheric Administration, 2015).

\begin{tabular}{|c|c|c|c|c|c|c|}
\hline \multirow[b]{2}{*}{ Season } & \multicolumn{5}{|c|}{ Temp $\left({ }^{\circ} \mathrm{C}\right)$} & \multirow{2}{*}{$\frac{\text { Precipitation }(\mathrm{mm})}{4 \mathrm{wk}}$} \\
\hline & $\overline{1-14 \mathrm{~d} \text { avg }}$ & $15-28 \mathrm{~d}$ avg & 4 wk avg & 4 wk max & $4 \mathrm{wk}$ min & \\
\hline Summer 2013 & 32.1 & 30.0 & 31.1 & 39.4 & 20.6 & 20 \\
\hline Fall 2013 & 19.8 & 15.8 & 17.8 & 28.9 & 1.1 & 115 \\
\hline Summer 2014 & 28.7 & 30.2 & 29.4 & 37.2 & 20.6 & 33 \\
\hline Fall 2014 & 20.3 & 12.5 & 16.4 & 29.4 & -1.6 & 81 \\
\hline Spring 2015 & 22.1 & 21.4 & 21.7 & 31.7 & 10.0 & 121 \\
\hline Summer 2015 & 30.6 & 28.5 & 29.5 & 41.1 & 21.1 & 70 \\
\hline Fall 2015 & 21.4 & 19.1 & 20.2 & 30.0 & 11.1 & 260 \\
\hline
\end{tabular}


allele for the double flower gene (Blfo). Therefore, only double/ semidouble (>eight petals) flowers were considered in petal number data because petal number in single flowers (five to eight petals) changes very little. Flower production was determined by randomly selecting three new shoots from each plant that had grown since the last pruning in February/March, June, and September.

Statistical analysis. All statistical analyses were performed using JMP software (version 12.0.1; SAS Institute, Cary, $\mathrm{NC}$ ). A Shapiro-Wilk W test was performed to test the normality of raw and transformed data (Razali and Wah, 2011). Correlation coefficients of all six components were generated from Pearson product-moment correlation analysis. Two-way factorial ANOVA was conducted to compare among the population and seasonal means as well as to assess the interaction effect.

The genetic variance of the measured flower traits was estimated using the restricted maximum likelihood estimation (REML) analysis with the following model $(y=\mu+$ $\sigma_{\mathrm{FP}}^{2}+\sigma_{\mathrm{PP}}^{2}+\sigma_{\mathrm{Prog}[\mathrm{FP}, \mathrm{PP}]}^{2}+\sigma_{\text {Season }}^{2}+\sigma_{\text {Season*FP }}^{2}+\sigma_{\text {Season*PP }}^{2}+$ $\sigma_{\text {Season*Prog[FP,PP }]}^{2}+\sigma_{\text {Error }}^{2}$ ) (Dieters et al., 1995; Littell et al., 2006) with JMP software (version 12.0.1; SAS Institute). Parental [female parent (FP), pollen/male parent (PP)] variances were regarded as additive variance $\left(V_{\mathrm{a}}\right)$, progeny (Prog) variance was regarded as nonadditive variance $\left(V_{\mathrm{d}}\right)$, variance due to parents and progeny was regarded as genotypic variance $\left(V_{\mathrm{g}}\right)$, and the interaction of genotype (FP, PP, or Progeny) and the season/pruning severity was treated as the genetic-environmental variance $\left(V_{\mathrm{g}} \times e\right)$. The narrow-sense heritability was calculated as $h^{2}=V_{\mathrm{a}} / V_{\mathrm{p}}$ and broad-sense heritability was calculated as $H^{2}=\left(V_{\mathrm{a}}+V_{\mathrm{d}}\right) / V_{\mathrm{p}}$, where $V_{\mathrm{p}}=V_{\mathrm{a}}+V_{\mathrm{d}}+\left(V_{\mathrm{g}} \times e / E\right.$, where $E$ indicates the number of environments (seasons or pruning severity) used in the analysis (Connor et al., 2005; Hallauer et al., 2010; Holland et al., 2003).

\section{Results}

\section{Normality analysis}

Normality of data for petal number, flower dry weight, and number of flowers per inflorescence, but not flower diameter was improved after either $\log _{10}$ or square root transformation (data not shown). As $\log _{10}$ transformation was better, subsequent statistical analyses were conducted with raw flower diameter data and $\log _{10}$ transformed petal number, flower dry weight, and number of flowers per inflorescence data.

\section{Correlation analysis}

There is a positive correlation between flower dry weight with flower diameter $(R=0.47)$ and petal number $(R=0.44)$, whereas there was a weak negative correlation between flower diameter and petal number $(R=-0.11)$ reflecting a weak tendency of the wider (greater diameter) flowers to have fewer petals in this rose germplasm and vice versa (Table 3). As flower production traits (flowers per primary/secondary/tertiary inflorescence) were well correlated among each other $(R=0.85$, 0.86 , and 0.74 ), all subsequent analyses were done using the total number of flowers of the combined inflorescence. Flower size and flower production data were either weakly or not correlated (Table 3 ).

\section{Flower size}

GENERAL LINEAR ANALYSIS OF FLOWER SIZE. The preliminary experiment focused on the number of petals in 2013 and 2014. Two way factorial analysis of petal count data for three seasons (Summer 2013, Fall 2013, and Summer 2014) indicated that petal numbers varied among populations and seasons but that there was no interaction (Table 4). Examination of the seasonal effect indicated that there were no differences between the petal counts for Summers 2013 and 2014 but that these differed from the counts from Fall 2013. Therefore, data collected from Summers 2013 and 2014 were averaged as warm season data. Data collected from Fall 2013 was regarded as cool season data. The analysis with the combined data confirmed the differences among rose populations and the seasons and the lack of an interaction effect for petal counts (Tables 5 and 6). There was a $19.6 \%$ decrease in petal number in the warm season as compared with the cool season (Table 6).

The expanded work included flower diameter, petal number, and flower dry weight in 2015. Preliminary analysis of variance indicated spring and fall data were not different in flower

Table 3. Pairwise correlations among flower diameter, petal number, flower dry weight, and the number of flowers per primary/secondary/tertiary inflorescence of diploid rose at College Station, TX, in 2015.

\begin{tabular}{lccccc}
\hline & Petals (no.) & Flower dry wt (mg) & Flowers (no./primary) & Flowers (no./secondary) & Flowers (no./tertiary) \\
\hline Flower diam (cm) & - & $0.44^{* * *}$ & NS & NS & NS \\
Petals (no.) & $0.11^{* * *}$ & $0.47^{* * *}$ & NS & NS & NS \\
Flower dry wt (mg) & & & $0.22^{*}$ & $0.85^{* * *}$ & $0.74^{* * *}$ \\
Flowers (no./primary) & & & & $0.86^{* * *}$ \\
Flowers (no./secondary) & & & & \\
\hline
\end{tabular}

Ns, ${ }^{*}, * *, * * *$ Nonsignificant or significant at $P \leq 0.05,0.01$, or 0.001 , respectively.

Table 4. Analyses of variance $F$-ratio results for population, season, and population by season interaction effects among Summer 2013, Fall 2013, and Summer 2014 at College Station, TX for petal number of 10 diploid rose populations.

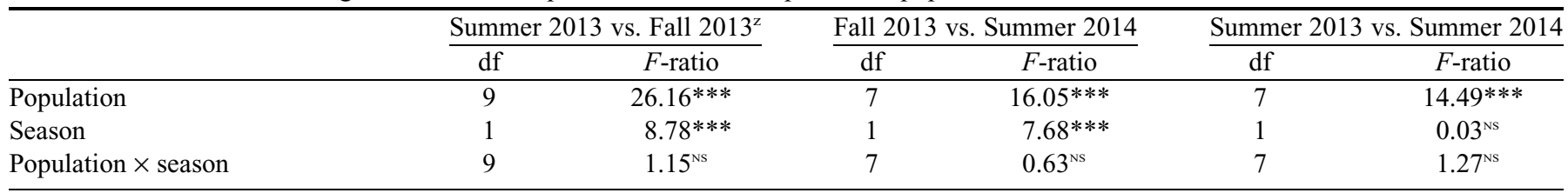

$\mathrm{df}=$ degree(s) of freedom.

${ }^{\mathrm{z}} \log _{10}$ transformed data of petal number was used. Only petal numbers larger than eight were considered.

Ns, * ${ }^{* *},{ }^{* * *}$ Nonsignificant or significant at $P \leq 0.05,0.01$, or 0.001 , respectively. 
diameter, petal number, or flower dry weight, so these seasons were averaged to create the cool season data and the analysis run to compare cool (mean temperature $21^{\circ} \mathrm{C}$ ) vs. warm (mean temperature $29.5^{\circ} \mathrm{C}$ ) season effects. The combined analysis indicated that all three measures of flower size varied with population and season (warm vs. cool) and that a significant temperature interaction effect existed for flower diameter, but not for petal number or flower dry weight (Table 7).

As expected, populations differed in mean flower size. Over all populations, warm season flower size decreased by $17.7 \%$ in flower diameter, $17.3 \%$ to $19.6 \%$ in petal number, and

Table 5. Analysis of variance $F$-ratio results for cool and warm season effect on the petal number of 10 diploid rose populations during 2013 and 2014 at College Station, TX.

\begin{tabular}{lccc}
\hline & df & Variance & $F$-ratio \\
\hline Population $^{z}$ & 9 & 10.34 & $24.35^{* * *}$ \\
Season $($ cool vs. warm) & 1 & 0.72 & $15.21^{* * *}$ \\
Population $\times$ season & 9 & 0.26 & $0.61^{\text {Ns }}$ \\
\hline
\end{tabular}

$\mathrm{df}=$ degree(s) of freedom.

${ }^{\mathrm{z}} \log _{10}$ transformed data of petal number was used. Only petal numbers larger than eight were considered.

Ns, * ${ }^{* * *}{ }^{* * *}$ NS or significant at $P \leq 0.05,0.01$, or 0.001 , respectively.

Table 6. Petal number for 10 diploid rose populations grown at College Station, TX, during 2013 and 2014.

\begin{tabular}{lcccc}
\hline Population $^{z}$ & Petal $^{\mathrm{y}}($ no. $)$ & Warm & Cool & Decrease (\%) \\
\hline OB $\times$ J3-6 & $27 \mathrm{f}$ & 25 & 29 & 14.7 \\
TF $\times$ J3-6 & $39 \mathrm{def}$ & 32 & 47 & 30.2 \\
OB $\times$ M4-4 & $271 \mathrm{f}$ & 22 & 31 & 30.6 \\
$\mathrm{SC} \times \mathrm{M} 4-4$ & $57 \mathrm{bc}$ & 47 & 67 & 30.5 \\
$\mathrm{~J} 4-6 \times \mathrm{RF}$ & $33 \mathrm{ef}$ & 27 & 40 & 33.0 \\
$\mathrm{~J} 3-3 \times \mathrm{RF}$ & $46 \mathrm{cde}$ & 42 & 49 & 13.9 \\
VS $\times$ J14-3 & $78 \mathrm{a}$ & 86 & 71 & -21.0 \\
$\mathrm{~J} 14-3 \times \mathrm{VS}$ & $62 \mathrm{ab}$ & 50 & 75 & 33.0 \\
$\mathrm{~J} 14-3 \times \mathrm{SC}$ & $54 \mathrm{~cd}$ & 50 & 58 & 12.9 \\
M4-4 $\times \mathrm{SC}$ & $35 \mathrm{ef}$ & 27 & 43 & 36.4 \\
Mean & 45 & 41 & 51 & $19.6^{*}$ \\
\hline
\end{tabular}

${ }^{\mathrm{z}} \mathrm{J} 14-3$ = J06-20-14-3, J4-6 = J06-28-4-6, J3-6 = J06-30-3-6, J3-3 = J06-30-3-3, OB = 'Old Blush', LC = 'Little Chief', RF = 'Red Fairy', $\mathrm{TF}=$ 'The Fairy', $\mathrm{SC}=$ 'Sweet Chariot', VS = 'Vineyard Song'.

${ }^{y}$ Levels not connected by the same letter are significantly different at $P \leq 0.05$. Means are derived from raw data; $\log _{10}$ transformed data of petal number was used. Only petal numbers larger than eight were considered. Means are calculated with raw data.

ss, *Nonsignificant or significant at $P \leq 0.05$.
$32.1 \%$ in flower dry weight as compared with flower size in the cool season (Tables 6 and 8).

As heat tolerance is the differential response of the populations to heat stress, this would be statistically confirmed by a significant $G \times E$ (population $\times$ season) effect which is seen only for flower diameter. Although flower diameter decreased because of high temperature for all populations, the degree varied from a $10.7 \%$ to a $28.0 \%$ decrease (Table 8 ). Of the nine populations, four populations had flower diameter decreases of less than $12.5 \%$ and two had flower diameter decreases of greater than $25 \%$. It is these four populations with the least change in flower size which would be considered the most heat tolerant with a more stable flower size throughout the year (Table 8). Interestingly, these more heat-tolerant populations, as measured by their change in flower diameter, are not necessarily those with less heat induced loss in petal number or flower dry weight.

GeNeTIC ANALYSIS OF FLOWER Size. All flower size measurements from 2013 to 2015 had a low to moderate narrow-sense $(0.26-0.53)$ and a moderately high to high broad-sense $(0.70-$ $0.91)$ heritability indicating substantial nonadditive genetic variation (Table 9). The $G \times E$ effect varied from a high of $\approx 35 \%$ for flower diameter, to $\approx 18 \%$ for flower dry weight, and $16 \%$ to $23 \%$ for the number of petals. In all cases, the total genetic variance was larger than the $G \times E$ variance, indicating that selection in one season could be effective for these traits. Petal number had the highest broad-sense heritability of 0.91 and the lowest $V_{\mathrm{g}} \times e / V_{\mathrm{g}}$ ratio of 0.20 in 2015 . Flower diameter had the lowest broad-sense heritability $(0.70)$ and had the highest $V_{\mathrm{g}} \times e / V_{\mathrm{g}}$ ratio $(0.85)$ which indicated that flower diameter was differentially affected by heat stress more than the other traits (Table 9).

\section{Flower production}

General Linear analysis of flower production. The number of flowers per inflorescence varied among the populations and between seasons, but in a population-specific fashion (significant population $\times$ season effect) (Table 10).

The mean number of flowers per new growth inflorescence over all seasons varied from a high of 22.3 ('Sweet Chariot' $\times$ M4-4) to a low of 8.6 ('Old Blush' $\times$ 'Red Fairy') (Table 11). In general, the number of flowers per inflorescence was highest in the spring (23.2) and decreased as the season progressed (14.9 and 10.8 in the summer and fall, respectively) (Table 11). This general pattern was consistent with seven of the nine populations. For the other two populations, one ('Old Blush' $\times$ 'Red Fairy') produced similar number of flowers per inflorescence over all seasons, whereas the other (J14-3 × 'Red Fairy') produced equal numbers of flowers in the spring and fall. Because the number of flowers per inflorescence across all populations was not consistently less in the warm summer season as compared with the cooler spring and the fall, the change in flower production was not clearly caused by high temperature stress.

A major confounding factor in this data is the pruning severity that the plants experienced in the different seasons. In the spring pruning, plants were pruned back to thicker 
stems (1.0-1.4 cm diameter) as compared with the light pruning $(0.4-0.6 \mathrm{~cm}$ diameter) conducted in the summer and fall seasons. Therefore, an ANOVA was conducted between severe pruning (spring) and light pruning (summer/fall) seasons. As expected from the previous analysis there were large differences among populations. The pruning severity effect was

Table 8. Mean flower diameter $(\mathrm{cm})$, petal number, and flower dry weight $(\mathrm{mg})$ for the cool and warm seasons over nine diploid rose populations grown at College Station, TX, in 2015.

\begin{tabular}{|c|c|c|c|c|c|c|c|c|c|}
\hline \multirow[b]{2}{*}{ Population $^{y}$} & \multicolumn{3}{|c|}{ Flower diam $(\mathrm{cm})^{\mathrm{z}}$} & \multicolumn{3}{|c|}{ Petals (no.) } & \multicolumn{3}{|c|}{ Flower dry wt (mg) } \\
\hline & Cool & Warm & $\begin{array}{c}\text { Decrease } \\
(\%)\end{array}$ & Cool & Warm & $\begin{array}{c}\text { Decrease } \\
(\%)\end{array}$ & Cool & Warm & $\begin{array}{c}\text { Decrease } \\
(\%)\end{array}$ \\
\hline $\mathrm{OB} \times \mathrm{J} 3-6$ & 4.45 & 3.92 & $11.9 *$ & 24.6 & 19.7 & 19.8 & 102 & 75 & 26.8 \\
\hline $\mathrm{SC} \times \mathrm{M} 4-4$ & 3.78 & 3.31 & $12.3 *$ & 52.7 & 47.4 & 10.1 & 65 & 53 & 19.2 \\
\hline $\mathrm{J} 4-6 \times \mathrm{RF}$ & 3.57 & 3.19 & $10.7 *$ & 32.3 & 30.5 & 5.8 & 62 & 41 & 32.8 \\
\hline $\mathrm{J} 14-3 \times \mathrm{VS}$ & 3.90 & 3.25 & $16.7 *$ & 57.8 & 48.3 & 16.3 & 93 & 61 & 34.8 \\
\hline $\mathrm{J} 14-3 \times \mathrm{SC}$ & 3.74 & 3.31 & $11.6^{*}$ & 52.8 & 41.8 & 20.8 & 83 & 45 & 45.6 \\
\hline $\mathrm{J} 14-3 \times \mathrm{LC}$ & 3.56 & 2.86 & $19.7 *$ & 51.4 & 39.8 & 22.5 & 69 & 59 & 15.2 \\
\hline $\mathrm{J} 14-3 \times \mathrm{RF}$ & 3.69 & 2.66 & $28.0 *$ & 47.0 & 37.7 & 19.9 & 88 & 60 & 31.7 \\
\hline $\mathrm{OB} \times \mathrm{RF}$ & 4.08 & 3.14 & $23.1 *$ & 42.2 & 33.1 & 21.5 & 134 & 79 & 41.4 \\
\hline M4-4 × 97/7-2 & 3.28 & 2.41 & $26.5^{*}$ & - & - & - & 33 & 22 & 34.3 \\
\hline Overall & 3.78 & 3.12 & $17.7^{*}$ & 45.1 & 37.3 & $17.3^{*}$ & 81 & 55 & $32.1^{*}$ \\
\hline
\end{tabular}

${ }_{\mathrm{z}}$ Data from spring and fall were combined as cool season data. Analysis done with raw data of flower diameter, $\log _{10}$ transformed data of petal number, and flower dry weight. Only petal numbers larger than eight were considered. Means are calculated with raw data.

' ${ }_{J} 14-3$ = J06-20-14-3, J4-6 = J06-28-4-6, J3-6 = J06-30-3-6, OB = 'Old Blush', LC = 'Little Chief', $\mathrm{RF}=$ 'Red Fairy', $\mathrm{SC}=$ 'Sweet Chariot', VS = 'Vineyard Song'.

ns, *Nonsignificant or significant between seasons at $P \leq 0.05$. highly significant with the hard pruning done in the spring stimulating larger inflorescences (21.3 flowers per inflorescence) than the light pruning (10.9 flowers per inflorescence) done in the summer and fall seasons (Tables 12 and 13). The populations had between $40 \%$ and $61 \%$ (mean $49 \%$ ) fewer flowers per inflorescence after a light pruning as compared with a hard pruning. Only one population $(\mathrm{OB} \times \mathrm{RF})$ had a nonsignificant decrease in flowers/ inflorescence although the flowers per inflorescence were low on average.

Genetic ANALysis OF FLOWER PRODUCTION. The number of flowers per inflorescence had a moderate narrow-sense (0.42) and a moderately high broad-sense heritability (0.75) (Table 14) similar to that observed with flower diameter, petal number, and flower dry weight (Tables 9 and 14) collected on the same populations. The nonadditive genetic effect of the number of flowers per inflorescence was similar to the additive effect (Table 14). The $G \times E$ effect (flower number $\times$ pruning severity) for the number of flowers accounted about $\approx 36 \%$ of the total variance (Table 14)

Table 9. Genetic variance for flower diameter, petal number, and flower dry weight ${ }^{\mathrm{z}}$ for cool and warm seasons in nine diploid populations in 2015 and for petal number in 2013-14 in 10 diploid rose populations at College Station, TX, field plots calculated by REML (restricted estimated maximum likelihood).

\begin{tabular}{lcccc}
\hline & Flower diam $(\mathrm{cm}) 2015$ & Petals (no.) 2013-14 & Petals (no.) 2015 & Flower dry wt (mg) 2015 \\
\hline Observed & 680 & 422 & 454 & 676 \\
$r^{2}$ & 0.81 & 0.87 & 0.90 & 0.84
\end{tabular}

$\mathrm{FP}^{\mathrm{y}} \quad 10.8$

PP 11.2

Progeny (FP, PP) 18.9

Season $\quad 24.3$

$\mathrm{FP} \times$ season

$\mathrm{PP} \times$ season

Progeny $(\mathrm{FP}, \mathrm{PP}) \times$ season

$V_{\mathrm{a}} \quad 0.119$

$V_{\mathrm{d}} \quad 0.102$

$\begin{array}{ll}V_{\mathrm{g}} & 0.221\end{array}$

$\begin{array}{ll}V_{\mathrm{g}} & 0.315\end{array}$

$\begin{array}{ll}V_{\mathrm{g}} \times e & 0.188\end{array}$

$V_{\mathrm{g}} \times e / V_{\mathrm{g}} \quad 0.85$

$\begin{array}{ll}h^{2} & 0.38\end{array}$

$H^{2} \quad 0.70$
Percentage of total variance

$\begin{array}{rrr}22.5 & 1.8 & 41.4 \\ 3.1 & 20.7 & 0.8 \\ 40.9 & 55.8 & 28.0 \\ 10.5 & 6.2 & 11.5 \\ 0.2 & 0.0 & 0.0 \\ 0.7 & 0.0 & 1.0 \\ 22.2 & 15.5 & 17.3\end{array}$

Genetic variance

$\begin{array}{lll}0.019 & 0.016 & 0.033 \\ 0.030 & 0.039 & 0.022 \\ 0.049 & 0.054 & 0.056 \\ 0.058 & 0.060 & 0.063 \\ 0.017 & 0.011 & 0.014 \\ 0.347 & 0.20 & 0.26\end{array}$

Heritability

$\begin{array}{lll}0.33 & 0.26 & 0.53\end{array}$

$0.85 \quad 0.91 \quad 0.88$

${ }_{\mathrm{z}}$ Raw data of flower diameter, $\log _{10}$ transformed data of petal number, and flower dry weight were used. Only petal numbers larger than eight were considered.

${ }^{\mathrm{y}} \mathrm{FP}=$ female parent, $\mathrm{PP}=$ pollen parent, $V_{\mathrm{a}}=$ parental variances, $V_{\mathrm{d}}=$ progeny variance, $V_{\mathrm{g}}=$ variance due to parents and progeny, $V_{\mathrm{g}} \times e=$ variance due to the interaction of genotype and environment, sum of the $\mathrm{FP} \times$ season, $\mathrm{PP} \times$ season, and progeny $\times$ season effects, $V_{\mathrm{p}}$ (phenotypic variance $)=\left(V_{\mathrm{a}}+V_{\mathrm{d}}+V_{\mathrm{g}} \times e / E\right), h^{2}=V_{\mathrm{a}} / V_{\mathrm{p}}, H^{2}=\left(V_{\mathrm{a}}+V_{\mathrm{d}}\right) / V_{\mathrm{p}}, E=$ number of seasons, $h^{2}=$ narrow-sense heritability, $H^{2}=$ broad-sense heritability. 
Table 10. Analyses of variance $F$-ratio results for population, season, and population by season interaction effect of nine diploid rose populations at College Station, TX, in 2015 for the number of flowers per inflorescence.

\begin{tabular}{lrr}
\hline & \multicolumn{2}{c}{ Flowers $\left(\right.$ no./inflorescence) ${ }^{\mathrm{z}}$} \\
\cline { 2 - 3 } & $\mathrm{df}$ & $F$-ratio \\
\hline Population & 8 & $20.31^{* * *}$ \\
Season & 2 & $27.43^{* * *}$ \\
Population $\times$ season & 16 & $7.24 * * *$ \\
\hline
\end{tabular}

${ }^{\mathrm{z}} \log _{10}$ transformed data of number of flowers per inflorescence was used.

ns, ${ }^{*},{ }^{* *},{ }^{* * *}$ Nonsignificant or significant at $P \leq 0.05,0.01$, or 0.001 , respectively.

Table 11. Changes of number of flowers per inflorescence in nine diploid rose populations among spring, summer, and fall at College Station, TX, in 2015. $\log _{10}$ transformed data were used for the analysis.

\begin{tabular}{lcccr}
\hline & \multicolumn{4}{c}{ Flowers (no./inflorescence) $^{\mathrm{z}}$} \\
\cline { 2 - 5 } Population $^{\mathrm{y}}$ & Population mean & Spring & Summer & \multicolumn{1}{c}{ Fall } \\
\hline OB $\times$ J3-6 & $9.9 \mathrm{e}$ & $14.0 \mathrm{a}$ & $10.9 \mathrm{a}$ & $4.7 \mathrm{~b}$ \\
$\mathrm{SC} \times \mathrm{M} 4-4$ & $22.3 \mathrm{a}$ & $35.6 \mathrm{a}$ & $19.3 \mathrm{~b}$ & $12.0 \mathrm{c}$ \\
$\mathrm{J} 4-6 \times \mathrm{RF}$ & $20.3 \mathrm{ab}$ & $32.0 \mathrm{a}$ & $23.9 \mathrm{a}$ & $4.8 \mathrm{~b}$ \\
$\mathrm{~J} 14-3 \times \mathrm{VS}$ & $16.7 \mathrm{bc}$ & $22.2 \mathrm{a}$ & $16.7 \mathrm{~b}$ & $11.2 \mathrm{c}$ \\
$\mathrm{J} 14-3 \times \mathrm{SC}$ & $17.8 \mathrm{bc}$ & $23.8 \mathrm{a}$ & $15.7 \mathrm{~b}$ & $13.7 \mathrm{~b}$ \\
$\mathrm{~J} 14-3 \times \mathrm{LC}$ & $13.4 \mathrm{~d}$ & $18.9 \mathrm{a}$ & $11.7 \mathrm{~b}$ & $9.8 \mathrm{~b}$ \\
$\mathrm{~J} 14-3 \times \mathrm{RF}$ & $18.3 \mathrm{bc}$ & $22.4 \mathrm{a}$ & $12.3 \mathrm{~b}$ & $20.4 \mathrm{a}$ \\
OB $\times \mathrm{RF}$ & $8.6 \mathrm{cde}$ & $14.3 \mathrm{a}$ & $3.7 \mathrm{a}$ & $7.7 \mathrm{a}$ \\
M4-4 $\times$ 97/7-2 & $18.9 \mathrm{bc}$ & $24.5 \mathrm{a}$ & $19.8 \mathrm{a}$ & $12.5 \mathrm{~b}$ \\
Overall & 16.5 & $23.2 \mathrm{a}$ & $14.9 \mathrm{~b}$ & $10.8 \mathrm{c}$ \\
\hline
\end{tabular}

${ }^{\mathrm{z}}$ LSMeans within the components connected by the same letter are not significantly different among population means or among seasons within a population at $P \leq 0.05$, with LSD adjustment. Means calculated from raw data.

${ }^{\mathrm{y}} \mathrm{J} 14-3$ = J06-20-14-3, J4-6 = J06-28-4-6, J3-6 = J06-30-3-6, OB = 'Old Blush', LC = 'Little Chief', RF = 'Red Fairy', $\mathrm{SC}=$ 'Sweet Chariot', VS $=$ 'Vineyard Song'.

Table 12. Analyses of variance $F$-ratio results for population, pruning severity $^{\mathrm{z}}$, and population by pruning interaction effect of nine diploid rose populations at College Station, TX, in 2015 for the number of flowers per inflorescence.

\begin{tabular}{lcc}
\hline & \multicolumn{2}{c}{ Flowers $($ no./inflorescence) } \\
\cline { 2 - 3 } & $\mathrm{df}$ & $F$-ratio \\
\hline Population & 8 & $33.14^{\mathrm{y} * *}$ \\
Pruning & 1 & $217.26^{* * *}$ \\
Population $\times$ pruning & 8 & $2.46^{*}$
\end{tabular}

$\mathrm{df}=$ degree(s) of freedom.

${ }^{\mathrm{z}}$ Hard pruning was done at the end of the winter in February/March and reduced plant size by $50 \%$ to $75 \%$ and light pruning was done in both June and September and reduced plant size by $25 \%$ to $40 \%$.

${ }^{\mathrm{y}} \log _{10}$ transformed data of number of flowers per inflorescence was used.

Ns, ${ }^{*},{ }^{* *},{ }^{* * *}$ Nonsignificant or significant at $P \leq 0.05,0.01$, or 0.001 , respectively.

indicating differences among populations/progeny in how they responded to the severity of the pruning in the different seasons and thus an ability to select for more stable flower numbers per inflorescence on new growth.

\section{Discussion}

As expected, flower size differed among populations and heat stress caused by summer temperatures caused flower size to decrease whether measured in terms of flower diameter $(\approx 18 \%)$, petal number $(17 \%$ to $20 \%)$, or flower dry weight $(\approx 32 \%)$ (Tables 6 and 8$)$. The decreased flower size is in agreement with a previous study on the same germplasm using a heat shock treatment to induce heat stress (Liang et al., 2017) and with other reports in both cut flower and garden roses (Greyvenstein, 2013; Greyvenstein et al., 2014; Shin et al., 2001). However, it is the existence of an interaction effect which confirms differential response of the tested families to heat stress. Work by Greyvenstein (2013) indicated that garden rose cultivars differed in their reaction to temperature in the field as measured by flower dry weight with higher temperatures leading to less flower dry weight. In this study as with the previous heat shock experiment done on the same germplasm, only flower diameter showed differences in heat stress response (heat tolerance) on the population basis. Although petal number and flower dry weight decreased under higher temperature conditions, there is little evidence of a differential population response among the primarily miniature rose germplasm examined. The petal number result is consistent with a previous study with cut rose germplasm (Gitonga et al., 2014). However, our results are inconsistent with the conclusions of Greyvenstein (2013) that cultivars differentially respond in flower size to heat stress as measured by flower dry weight. However, in that research, a wide range of cultivars and flower sizes (71-1210 mg) were studied, whereas the present study examined miniature germplasm populations with a narrow range of flower sizes $(22-134 \mathrm{mg})$.

The flower diameter, petal number, and flower dry weight showed low to moderate narrow-sense heritability $(0.35,0.26-$ 0.33 , and 0.53 ) and moderately high to high broad-sense heritability $(0.70,0.85-0.91$, and 0.88$)$ indicating important additive and nonadditive genetic effects (Table 9). This agrees with previous results reported on the genetic effects of petal number and flower diameter (Gitonga et al., 2014; HibrandSaint Oyant et al., 2008; Liang et al., 2017; Shupert, 2005). The $G \times E$ effect for flower diameter, petal number, and flower dry weight was a moderate $35 \%, 16 \%$ to $23 \%$, and $18 \%$, respectively, indicating genetic progress can be made by selecting for flower size in either cool or warm seasons. As with the heat shock experiment on this same germplasm (Liang et al., 2017), the only flower size parameter that showed a significant $G \times E$ effect was flower diameter. As flower diameter shows the most consistent population-based differential response to heat stress, the highest $G \times E$ genetic variance $(35 \%$ of total variance), is easy to measure in the field and is the most visible trait from a consumer perspective, it is the best flower size trait to use for selection of heat-tolerant roses that exhibit stable flower size throughout the year. Given that total genetic variation is several fold higher than $G \times E$ variance, selection for flower diameter would be effective irrespective of the season of selection but to develop a stable flower diameter over cool and warm seasons, selection for flower diameter during the both the cool and warm seasons would be required.

The number of flowers per primary, secondary, and tertiary inflorescence was well correlated with each other, so these data were combined into the flowers per inflorescence for our analysis. Flower production was highest in the spring and 
Table 13. Changes in number of flowers per inflorescence in nine diploid rose populations between hard pruned and light pruned plants at College Station, TX, in 2015. $\log _{10}$ transformed data were used.

\begin{tabular}{lccrc}
\hline & \multicolumn{4}{c}{ Flowers (no./inflorescence) } \\
\cline { 2 - 5 } Population $^{\mathrm{z}}$ & Population mean & Hard pruned $^{\mathrm{y}}$ & Light pruned & Decrease (\%) \\
\hline OB $\times$ J3-6 & $10.4 \mathrm{~cd}^{\mathrm{x}}$ & $13.6 \mathrm{a}$ & $7.3 \mathrm{~b}$ & 47 \\
$\mathrm{SC} \times \mathrm{M} 4-4$ & $23.1 \mathrm{a}$ & $33.4 \mathrm{a}$ & $12.9 \mathrm{~b}$ & 61 \\
$\mathrm{~J} 4-6 \times \mathrm{RF}$ & $24.4 \mathrm{a}$ & $31.0 \mathrm{a}$ & $17.8 \mathrm{~b}$ & 43 \\
$\mathrm{~J} 14-3 \times \mathrm{VS}$ & $16.7 \mathrm{~b}$ & $21.6 \mathrm{a}$ & $11.8 \mathrm{~b}$ & 46 \\
$\mathrm{~J} 14-3 \times \mathrm{SC}$ & $18.2 \mathrm{~b}$ & $24.0 \mathrm{a}$ & $12.5 \mathrm{~b}$ & 48 \\
$\mathrm{~J} 14-3 \times \mathrm{LC}$ & $12.1 \mathrm{c}$ & $16.8 \mathrm{a}$ & $7.3 \mathrm{~b}$ & 56 \\
$\mathrm{~J} 14-3 \times \mathrm{RF}$ & $16.6 \mathrm{~b}$ & $21.1 \mathrm{a}$ & $12.0 \mathrm{~b}$ & 45 \\
OB $\times \mathrm{RF}$ & $8.0 \mathrm{~d}$ & $10.0 \mathrm{a}$ & $6.0 \mathrm{a}$ & 40 \\
M4-4 $\times 97 / 7-2$ & $18.6 \mathrm{~b}$ & $24.6 \mathrm{a}$ & $12.6 \mathrm{~b}$ & 49 \\
Overall & 16.7 & $21.8 \mathrm{a}$ & $11.1 \mathrm{~b}$ & 49
\end{tabular}

$\overline{\mathrm{z}_{\mathrm{J}} 14-3}$ = J06-20-14-3, J4-6 = J06-28-4-6, J3-6 = J06-30-3-6, OB = 'Old Blush', LC = 'Little Chief', $\mathrm{RF}=$ 'Red Fairy', $\mathrm{SC}=$ 'Sweet Chariot', VS = 'Vineyard Song',

${ }^{y}$ Hard pruning was done at the end of the winter in February/March and reduced plant size by $50 \%$ to $75 \%$ and light pruning was done in both June and September and reduced plant size by $25 \%$ to $40 \%$. ${ }^{\mathrm{x}}$ LSMeans within the components connected by the same letter are not significantly different among population means or among seasons within a population at $P \leq 0.05$, with LSD adjustment. Means were calculated with raw data.

Table 14. Genetic variance for the number of flowers per inflorescence in nine diploid populations with two pruning severities $^{\mathrm{z}}$ at College Station, TX, in 2015 in the field experiment as calculated with restricted estimated maximum likelihood (REML) analysis.

\begin{tabular}{|c|c|}
\hline \multicolumn{2}{|c|}{ Flowers (no./inflorescence) ${ }^{\mathrm{y}}$} \\
\hline Observed & 1,110 \\
\hline$r^{2}$ & 0.71 \\
\hline \multicolumn{2}{|c|}{ Percentage of total variance } \\
\hline $\mathrm{FP}^{\mathrm{x}}$ & 28.7 \\
\hline PP & 3.0 \\
\hline Progeny (FP, PP) & 24.7 \\
\hline Pruning & 6.7 \\
\hline $\mathrm{FP} \times$ pruning & 0.0 \\
\hline $\mathrm{PP} \times$ pruning & 3.2 \\
\hline Progeny $(\mathrm{FP}, \mathrm{PP}) \times$ pruning & 33.7 \\
\hline
\end{tabular}

Genetic variance

$\begin{array}{ll}V_{\mathrm{a}} & 0.038 \\ V_{\mathrm{d}} & 0.029 \\ V_{\mathrm{g}} & 0.067 \\ V_{\mathrm{p}} & 0.033 \\ V_{\mathrm{g}} \times e & 0.044 \\ V_{\mathrm{g}} \times e / V_{\mathrm{g}} & 0.65\end{array}$

$h^{2}$

Heritability

$H^{2}$

0.42

0.75

${ }^{\mathrm{z}}$ Hard pruning was done at the end of the winter in February/March and reduced plant size by $50 \%$ to $75 \%$ and light pruning was done in June and September and reduced plant size by $25 \%$ to $40 \%$.

${ }^{\mathrm{y}} \log _{10}$ transformed data were used.

${ }^{\mathrm{x}} \mathrm{FP}=$ female parent, $\mathrm{PP}=$ pollen parent, heritability, $V_{\mathrm{a}}=$ parental variances, $V_{\mathrm{d}}=$ progeny variance, $V_{\mathrm{g}}=$ variance due to parents and progeny, $V_{\mathrm{g}} \times e=$ variance due to the interaction of genotype and pruning severity $=$ the sum of $\mathrm{FP} \times$ pruning, $\mathrm{PP} \times$ pruning, and progeny $(\mathrm{FP}, \mathrm{PP}) \times$ pruning, $V_{\mathrm{p}}($ phenotypic variance $)=\left(V_{\mathrm{a}}+V_{\mathrm{d}}+V_{\mathrm{g}} \times e / E\right)$, $h^{2}=V_{\mathrm{a}} / V_{\mathrm{p}}$, narrow-sense heritability, $H^{2}=\left(V_{\mathrm{a}}+V_{\mathrm{d}}\right) / V_{\mathrm{p}}$, broad-sense heritability, $E=$ number of environments (pruning severity). decreased as the season progressed. However, flower production per inflorescence was not directly affected by high temperature stress as the flower number per inflorescence in the warm summer season was not consistently less than the cool fall/spring seasons. In fact, the flower number per inflorescence in the warm season was less than that in the spring but more than that in the fall (Table 11). The major determinant of the flower number per inflorescence was the thickness of the stem from which the shoot grew. As the data were taken on only new growth since the last pruning (done February/March, June, and September for spring, summer, and fall), the diameter from which this growth emerged was thicker in the spring (1-1.4 cm diameter) as compared with the stem thickness after the light pruning $(0.4-0.6 \mathrm{~cm}$ diameter $)$ done in the summer and fall. There was a $40 \%$ to $61 \%$ decrease in flower number per new growth inflorescence after a light pruning as compared with a severe pruning. Another factor that would encourage more flower production in the spring growth as compared with the summer and fall growth is chilling temperatures that these spring shoots are exposed to during the winter months (Gudin, 1992). Therefore, the seasonal changes in the flower production traits were not considered as high temperature stress related and were strongly affected by the stem diameter from which the regrowth was derived as well as the chilling the shoots were exposed to before growth. The heritability was similar to that seen with the flower size traits and showed differential population responses indicating that the selection of higher and more consistent flower numbers per inflorescence is possible.

At Texas A\&M University, in the evaluation of rose cultivars for heat tolerance, flower productivity is rated as flower intensity which is the percent of the plant surface covered with flowers. This incorporates both flower size and number into one metric to simplify this assessment. This research clearly indicates that the ability of a rose to maintain its flower diameter under high temperature varies with genotype and can be genetically manipulated. The other factor affecting the flower intensity ratings would be the number of flowers per plant which is related to the number and sizes of the inflorescences on the plant. Unexpectedly, the number of flowers per inflorescence from new growth after pruning in this study was not directly related to the field temperature, but more to the pruning severity and subsequently the diameter of the wood from which it grew and perhaps also to exposure to chilling temperatures. Nevertheless the trait is heritable and thus able to be modified via breeding. Further studies are needed to study the effects of heat on both the number of flowers per inflorescence and the number of inflorescences per plant and how that interacts with flower size to identify the critical genes responsible for conditioning heat tolerance and to improve our ability to develop heat-tolerant roses.

Finally, it should be noted that the present study dealt with miniature rose germplasm, which as indicated by the work done 
by Greyvenstein (2013) on a larger range of flower sizes, may respond differently from the larger-flowered shrub or cut flower rose germplasm. Thus this study should be repeated using larger-flowered rose germplasm to verify that the present results with miniature germplasm is relevant to the largerflowered rose germplasm.

\section{Literature Cited}

Ahmad, I., J.M. Dole, M.A. Khan, M. Qasim, T. Ahmad, and A.S. Khan. 2010. Present status and future prospects of cut rose production in Punjab, Pakistan. HortTechnology 20:1010-1015.

Blom, T.J. and M.J. Tsujita. 2003. Cut rose production, p. 594-600. In: A.V. Roberts, T. Debener, and S. Gudin (eds.). Encyclopedia of rose science. Elsevier Academic Press, Oxford, United Kingdom.

Byrne, D.H., N.A. Anderson, and O. Greyvenstein. 2012. Thoughts on heat tolerance in roses. Rose Hybridizer Assn. Nwsl. 43(3):5-6.

Byrne, D.H., N. Anderson, M. Orwat, and V. Soules. 2010. Field assessment of black spot resistance in roses in a hot humid climate. Acta Hort. 870:115-120.

Connor, A.M., M.J. Stephens, H.K. Hall, and P.A. Alspach. 2005. Variation and heritabilities of antioxidant activity and total phenolic content estimated from a red raspberry factorial experiment. J. Amer. Soc. Hort. Sci. 130:403-411.

Debener, T. and M. Linde. 2009. Exploring complex ornamental genomes: The rose as a model plant. Crit. Rev. Plant Sci. 28:267-280.

Dela, G., E. Or, R. Ovadia, A. Nissim-Levi, D. Weiss, and M. OrenShamir. 2003. Changes in anthocyanin concentration and composition in 'Jaguar' rose flowers due to transient high-temperature conditions. Plant Sci. 164:333-340.

Dieters, M.J., T.L. White, R.C. Littell, and G.R. Hodge. 1995. Application of approximate variances of variance components and their ratios in genetic tests. Theor. Appl. Genet. 91:15-24.

Gitonga, V.W., C.F. Koning-Boucoiran, K. Verlinden, O. Dolstra, R.G. Visser, C. Maliepaard, and F.A. Krens. 2014. Genetic variation, heritability and genotype by environment interaction of morphological traits in a tetraploid rose population. BMC Genet. 15:146-159.

Greyvenstein, O.F.C. 2013. Phenotyping of high temperature susceptibility in garden roses (Rosa $\times$ hybrida). Texas A\&M Univ., College Station, PhD Diss.

Greyvenstein, O.F.C., H.B. Pemberton, T.W. Starman, G. Niu, and D.H. Byrne. 2014. Effect of two-week high-temperature treatment on flower quality and abscission of Rosa L. 'Belinda's Dream' and 'RADrazz' (KnockOut ${ }^{\circledR}$ ) under controlled growing environments. HortScience 49:701-705.

Gudin, S. 1992. Influence of bud chilling on subsequent reproductive fertility in roses. Sci. Hort. 51:139-144.

Gudin, S. 2000. Rose: Genetics and breeding. Plant Breed. Rev. 17:159-190.

Hallauer, A.R., M.J. Carena, and J.B. Miranda Filho. 2010. Means and variances, p. 33-67. In: A.R. Hallauer, M.J. Carena, and J.B. Miranda Filho (eds.). Quantitative genetics in maize breeding. Springer, New York, NY.

Heinrichs, F. 2008. International statistics flower and plants. AIPH 56:16-90.
Hibrand-Saint Oyant, L., L. Crespel, S. Rajapakse, L. Zhang, and F. Foucher. 2008. Genetic linkage maps of rose constructed with new microsatellite markers and locating QTL controlling flowering traits. Tree Genet. Genomes 4:11-23.

Hodges, A.W., C.R. Hall, and M.A. Palma. 2015. Economic contributions of the green industry in the United States in 2013. HortTechnology 25:805-814.

Holland, J.B., W.E. Nyquist, and C.T. Cervantes-Martínez. 2003. Estimating and interpreting heritability for plant breeding: An update. Plant Breed. Rev. 22:9-112.

Hutton, S. 2012. The future of the rose industry. Amer. Rose 41:36-37. Krussmann, G. 1981. The complete book of roses. Timber Press, Portland, OR.

Liang, S., X. Wu, and D.H. Byrne. 2017. Flower-size heritability and floral heat-shock tolerance in diploid roses. HortScience 52:682-685.

Littell, R.C., G.A. Milliken, W.W. Stroup, R.D. Wolfinger, and O. Schabenberber. 2006. SAS system for mixed models. 2nd ed. SAS Inst., Cary, NC.

Ma, N., W. Chen, T. Fan, Y. Tian, S. Zhang, D. Zeng, and Y. Li. 2015. Low temperature-induced DNA hypermethylation attenuates expression of RhAG, an AGAMOUS homolog, and increases petal number in rose (Rosa hybrida). BMC Plant Biol. 15:237-249.

Marissen, N. 2001. Effects of pre-harvest light intensity and temperature on carbohydrate levels and vase life of cut roses. Acta Hort. 543:331-336.

Moe, R. 1975. The effect of growing temperature on keeping quality of cut roses. Acta Hort. 41:77-92.

National Oceanic and Atmospheric Administration. 2015. Climate data, date range 1 July 2013 to 20 Dec. 2015. 30 Dec. 2015. <http:// www.ncdc.noaa.gov/cdo-web/search>.

Pemberton, H.B. and J. Karlik. 2015. A recent history of the changing trends in the USA garden rose sales, types, and production methods. Acta Hort. 1064:223-234.

Pemberton, H.B., J.W. Kelly, and J. Ferare. 2003. Pot rose production, p. 587-593. In: A.V. Roberts, T. Debener, and S. Gudin (eds.). Encyclopedia of rose science. Elsevier Academic Press, Oxford, United Kingdom.

Razali, N.M. and Y.B. Wah. 2011. Power comparisons of ShapiroWilk, Kolmogorov-Smirnov, Lilliefors and Anderson-Darling tests. J. Stat. Modeling Analytics 2:21-33.

Roberts, A.V., T. Debener, and S. Gudin. 2003. Introduction, p. vi-vii. In: A.V. Roberts, T. Debener, and S. Gudin (eds.). Encyclopedia of rose science. Elsevier Academic Press, Oxford, United Kingdom.

Shepherd, R.E. 1954. History of the rose. Macmillan, New York, NY. Shin, H.K., J.H. Lieth, and S.H. Kim. 2001. Effects of temperature on leaf area and flower size in rose. Acta Hort. 547:185-191.

Shupert, D. 2005. The inheritance of several traits in three diploid interspecific rose populations. Texas A\&M Univ., College Station. MS Diss.

Vineland Research and Innovation Centre. 2013. The innovation report. Vineland Res. Innovation Ctr., Vineland Station, ON, Canada.

Wahid, A., S. Gelani, M. Ashraf, and M. Foolad. 2007. Heat tolerance in plants: An overview. Environ. Exp. Bot. 61:199-223.

Zlesak, D.C. 2006. Rosa, p. 695-740. In: N. Anderson (ed.). Flower breeding and genetics. Springer, Amsterdam, The Netherlands. 